\title{
WATER MANAGEMENT PLAN FOR OLIVE ORCHARDS IN A SEMI-MOUNTAINOUS AREA OF CRETE, GREECE
}

\author{
KOURGIALAS N.N. ${ }^{*}$ \\ KARATZAS G.P. \\ MORIANOU G.
}

School of Environmental Engineering, Technical University of Crete Polytechneioupolis, 73100 Chania, Greece.
Received: 03/11/2014

Accepted: $16 / 12 / 2014$

Available online: 26/02/2015 *to whom all correspondence should be addressed: e-mail: nektarios.kourgialas@enveng.tuc.gr

\section{ABSTRACT}

In the present work the physically based distributed rainfall-runoff modeling system, MIKE SHE, is used to simulate the surface runoff at a semi-mountainous impermeable area of Tavronitis River basin in CreteGreece. The objective of this surface flow model is to develop an appropriate irrigation plan for olive trees. For the model calibration, a simulation time of one year (01/09/2000 - 31/08/2001) was considered, while for the model verification a two-year period (01/09/2001 - 31/08/2003). During these periods river flow measurements were obtained at two specified locations. These measurements were employed as targets for calibration and verification of the surface flow model. After the successful calibration and validation processes, the 2D maps of the overland flow were produced. Using these maps, the locations of significant surface water accumulation in the study region and for a specific time period were identified. Next, these locations were proposed for the construction of potential small hydraulic structures (dam or/and reservoir), for covering the irrigation needs of olive trees in the study area.

Keywords: MIKE SHE model; irrigation; hydraulic structures; rainfall-runoff modeling; overland flow

\section{Introduction}

Hydrologic modeling has become an essential tool in watershed management. Specifically, for mediumsized catchments $\left(10^{2}-10^{3} \mathrm{~km}^{2}\right)$, rainfall-runoff models of semi-distributed type seem to be more reliable for operational activities, provided that an updating procedure can be adopted (Kourgialas and Karatzas, 2011). The water resources around the world are under increasing pressure due to the rapid population and economic growth. Thus, the continuous increase in the water demand for human and agricultural needs has led to the over-pumping of water, resulting in the depletion of groundwater reserves and disrupting the balance of the hydrologic cycle (Graham and Butts 2005; Kourgialas and Karatzas, 2014).

The distributed watershed hydrological model MIKE SHE is capable of simulating the various aspects of the hydrological cycle within a watershed (DHI, 2007). MIKE SHE has widely been used to study the hydrological responses to changes of land use or land cover and for different irrigation practices (Jayatilaka et al., 1998; Graham and Butts, 2005). Singh et al., (1999) introduced a modelling system applied to a large irrigation project in Central India with the use of MIKE-SHE. It has also been applied for sustainable surface/ground-water management and spatial scale effects (Demetriou and Punthakey, 1999; Vázquez and Feyen, 2007; Frana, 2012; Rahim et al., 2012).

The simulation of water resources for an effective irrigation management plan can enhance the agricultural productivity especially in small Mediterranean agricultural watersheds. These areas appear most vulnerable to global climate change and have been described as one of the main climate change 
"hot-spots" in Europe (Tsanis et al., 2011; Kourgialas et al., 2015). A typical example of a Mediterranean environment is the island of Crete, Greece where during the last decade an increased number of droughts has occurred. Based on the above, the study of the hydrological response for irrigation purposes is essential at a small river basin scale. In the present study, the overall objective is to evaluate the applicability of the MIKE SHE model in a small Mediterranean semi-mountainous impermeable agricultural area where runoff generation is dominated by the overland flow processes. In addition, based on the model results, special emphasis is given to an agricultural water management plan for olive trees, suggesting locations for potential construction of small scale hydraulic structures such as dams or/and reservoirs.

\section{Study area and data availability}

Tavronitis River Basin is located $20 \mathrm{~km}$ west of Chania city in Crete. The watershed has a total catchment area of $141 \mathrm{~km}^{2}$ with an elevation ranging from zero to $1400 \mathrm{~m} \mathrm{MSL}$ (Figure 1).

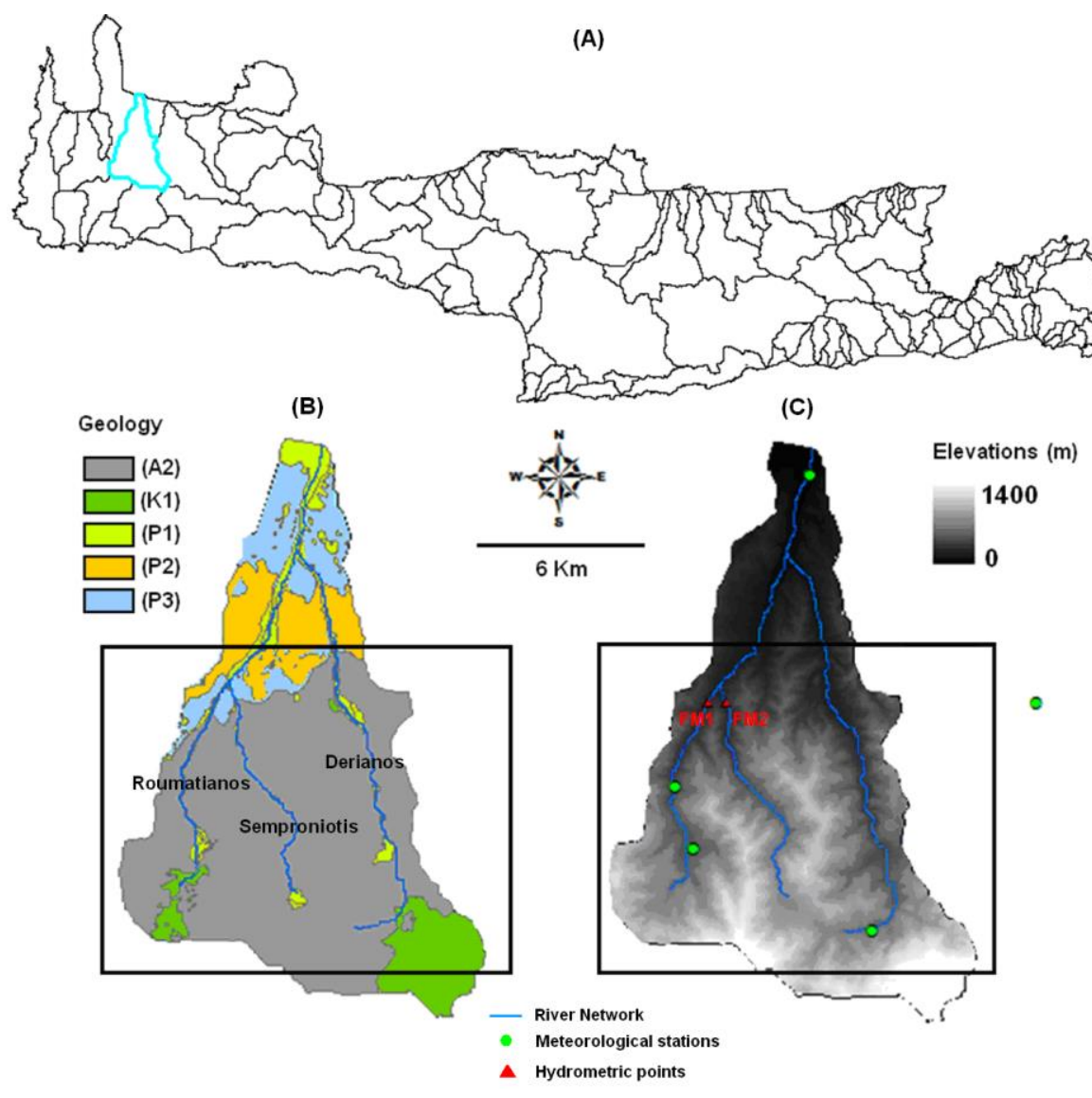

Figure 1. (A) The island of Crete and the Tavronitis River Basin, (B) Geological map of the Tavronitis River Basin, (C) The semi-mountainous part of the Tavronitis River Basin and the hydro-meteorological network

The climate is sub-humid Mediterranean with humid and relatively cold winters and dry and warm summers. The average annual precipitation is about $665 \mathrm{~mm}$ of which over $95 \%$ occurs between October and May (Chartzoulakis et al., 2001). The drainage network of the basin consists of Tavronitis River as the main channel and 3 tributaries (Roumatianos, Semproniotis, and Derianos) all of which are ephemeral streams. The geological formations of Tavronitis basin are classified based on their permeability as follows (Figure 1):

$>$ Karstic formations of high to moderate permeability (K1) 
$>$ Granular alluvial deposits of ranging permeability (P1), miocene deposits of moderate to low permeability (P2), and granular non-alluvial deposits of small to very small permeability (P3)

$>$ Impermeable formations of small to very low permeability (A2)

Tavronitis River Basin contributes to significant surface water supplies and this is due to the extended impermeable (A2) zone that exists at the semi-mountainous area of the basin (Figure 1). This area is crossed by the tributaries of Semproniotis, Roumatinos and Derianos. These ephemeral streams generate significant amounts of overland water. Based on this, the aim of this study is the overland simulation of this impermeable (A2) zone which in turn can lead to an effective agricultural management plan for the downstream area where the main cultivation is the olive tree.

For the simulation needs, the stream flow data (01/09/2000 - 31/08/2003) at two different locations (Roumatianos - FM1 and Semproniotis - FM2 tributaries) and the corresponding meteorological data from five surrounding stations were employed (Figure 1).

\section{The Methodology}

\subsection{Description of MIKE SHE}

MIKE SHE, developed by DHI Water \& Environment, is an advanced, deterministic, fully-distributed and physically-based hydrological and water quality modeling system (Im et al., 2009). MIKE SHE covers the major processes in the hydrologic cycle and includes process models for evapotranspiration, overland flow, unsaturated flow, groundwater flow, and channel flow and their interactions. Each of these processes can be represented at different levels of spatial distribution and complexity, according to the goals of the modelling study, the availability of field data and the modeller's choices (Graham and Butts, 2005). MIKE SHE user interface allows the user to intuitively build the model description based on the user's conceptual model of the watershed. In this study, the simulation of overland flow was performed solving the diffusive wave approximation of the Saint Venant equations with the method of finite differences. Detailed descriptions of the modeling procedures and mathematical formulation can be found in the MIKE SHE user's manual (DHI, 2007) and associated publications (Abbott et al., 1986; Graham and Butts, 2005).

The integrated hydrological model MIKE SHE has been designed to be fully compatible with the files of GIS. Using GIS, inputs such as the model domain, the topography, the geology, the land uses, the Manning's roughness coefficient (M) which actually is the inverse of the more conventional Manning's coefficient (n), as well as the hydro-metorological information at specific locations were inserted in the model. A brief description of these input data is given in the following paragraphs.

The first step of the development is the delineation of the model domain which is the semi-mountainous impermeable area of the Tavronitis watershed. The Digital Elevation Model (DEM) was generated from a digitized 1:10.000 topographical map. Specifically, the altitudes of the study area range from 200-700 m MSL. Regarding the geology and land uses, remote sensing methods (aerial photographs) and the traditional field explorative geological mapping as well as the Corine land-use database provided by the European Environmental Agency (EEA, http://www.eea.europa.eu) were used to create the digital geological map and the land use map of the study area, respectively.

The Manning's roughness coefficient (M), was used as the resistance coefficient of overland flow, with typical values ranging between 100 and 10. The higher the Manning's coefficient (M) value the faster the overland flow is routed toward the nearest river reach; thus peak runoff flows are particularly affected. As the Manning's roughness coefficient (M) values are reduced, the surface runoff water takes more time to reach the stream, thus more water percolates into the ground (Sahoo et al., 2006). The values of Manning's roughness coefficient (M) that were input to the MIKE SHE model were determined from a systematic review of the literature (Pestana et al., 2014) as well as the land use map of the study area.

The daily rainfall data were obtained from three meteorological stations located inside the study area as well as from two meteorological stations found in adjacent basins. To simulate the amount of rainfall at 
each grid, the study area was divided based on the Thiessen polygon technique considering the location of the meteorological stations. The average daily temperature for the entire simulation period was also used as an input to the model.

Moreover, in the model setup the Net Rainfall Fraction (NRF) was used. This parameter is the fraction of rainfall that is available for infiltration and overland flow, accounting for leaf interception and evapotranspiration (ET), when (ET) is not explicitly simulated. Since in the present work no detailed evapotranspiration data are available the Net Rainfall Fraction (NRF) was used as an input parameter. This parameter was also selected as a model calibration parameter.

\subsection{Model Performance}

Different statistical tests and performance criteria were employed in order to determine the fit of the model to the observed measurements. These tests are: the mean error (ME), mean absolute error (MAE), root mean square error (RMSE), coefficient of correlation (R), Nash-Sutcliffe coefficient $\left(R^{2}\right)$, and standard deviation of the residuals (STDres). When the forecast is perfect, the ME and MAE values are equal to zero. Moreover, values of RMSE close to zero indicate a perfect fit. Regarding the value of $R$, if $R=1$ a perfect positive relationship exists, and $R=-1$ indicates a perfect negative relationship, or an inverse relationship between modelled and observed data. A value equal to 1 for Nash-Sutcliffe coefficient $\left(R^{2}\right)$, represents a perfect fit. Additionally, the STDres is a goodness-of-fit measure, where, the smaller the residual standard deviation is the better fit to field data (Moriasi et al., 2007; Abramowitz and Stegun, 2012; Fry et al., 2013).

\subsection{Model simulations - discretization}

The grid size for running the model was set equal to $50 \times 50 \mathrm{~m}$ to compromise between simulation accuracy and physical characteristics of the study area. The model was calibrated for the time period 01/09/2000 $31 / 08 / 2001$, and validated for the next two years (01/09/2001 - 31/08/2003) based on the available flow data at tributary Semproniotis and tributary Roumatinos. The 2D results of this overland simulation were then used for designing the appropriate olive trees water management plan, based on the construction of small scale hydraulic structures that could control the accumulated surface water.

\section{Results and discussion}

\subsection{Model calibration and validation}

A distributed modeling system such as MIKE SHE requires a large number of model parameters to be specified. The parameters of MIKE SHE have a clear physical interpretation and can be explicitly defined from field measurements. However, calibration is frequently required to better reproduce measured watershed variables and to improve simulation results since measured values may not be always available (Im et al., 2009).The intervals of the calibration and validation periods were chosen on the basis of availability of field data. The calibration was performed estimating the parameter Net Rainfall Fraction (NRF) such that the model results are in good agreement with the observed data (stream flow measurements) at selected locations (FM1, FM2) in Roumatianos and Semproniotis tributaries, respectively (Figure 2 ).

The calibration parameter value of NRF that gave the best degree of correlation between field river flow data and simulation results was equal to 0.92 . This can be explained by the fact that in the study area the vegetation coverage is relatively low and is dominated by the cultivation of olive trees. Given that olive trees have low evapotranspiration values compared to other horticultural crops (Tsanis et al., 1997), the low level of evapotranspiration, indicated through the calibration parameter, seems to be realistic. 

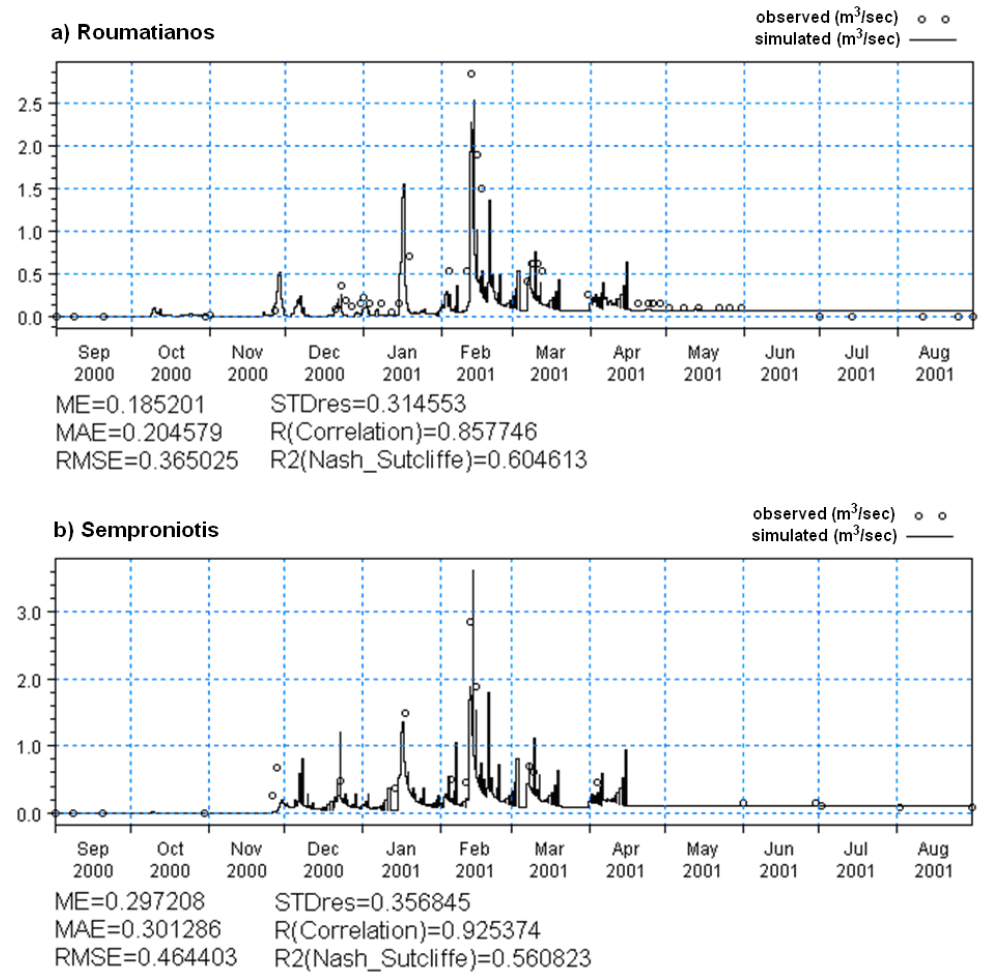

Figure 2.Observed and simulated streamflows in the tributaries (a) Roumatianos, and (b) Semroniotis for the calibration period (2000-2001)

a) Roumatianos

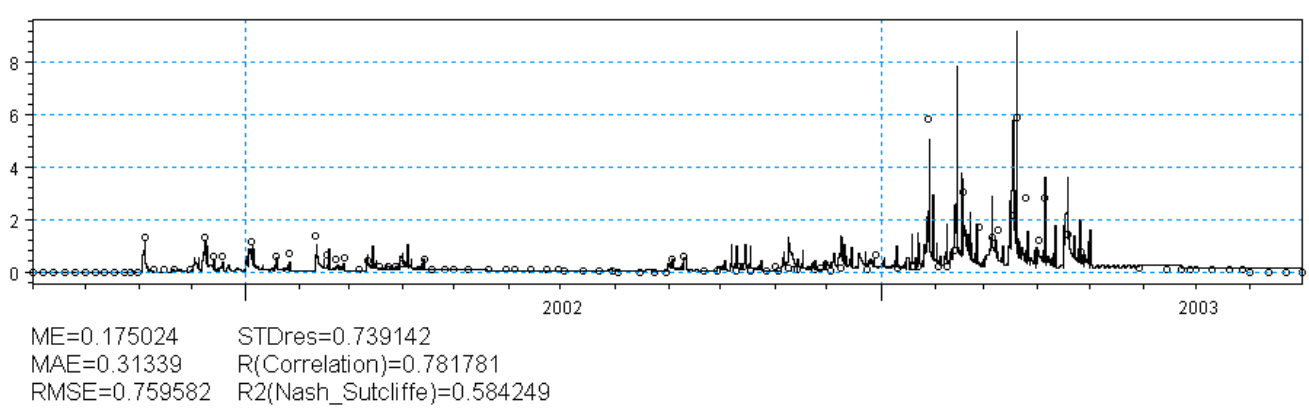

b) Semproniotis

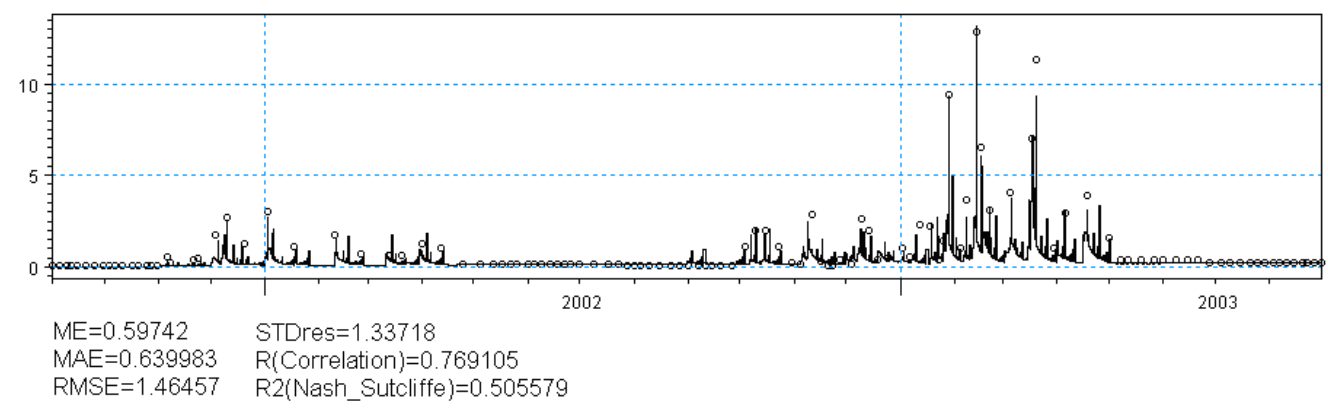

Figure 3. Observed and simulated streamflows in the tributaries (a) Roumatianos, and (b) Semroniotis for the validation period (2001-2003) 


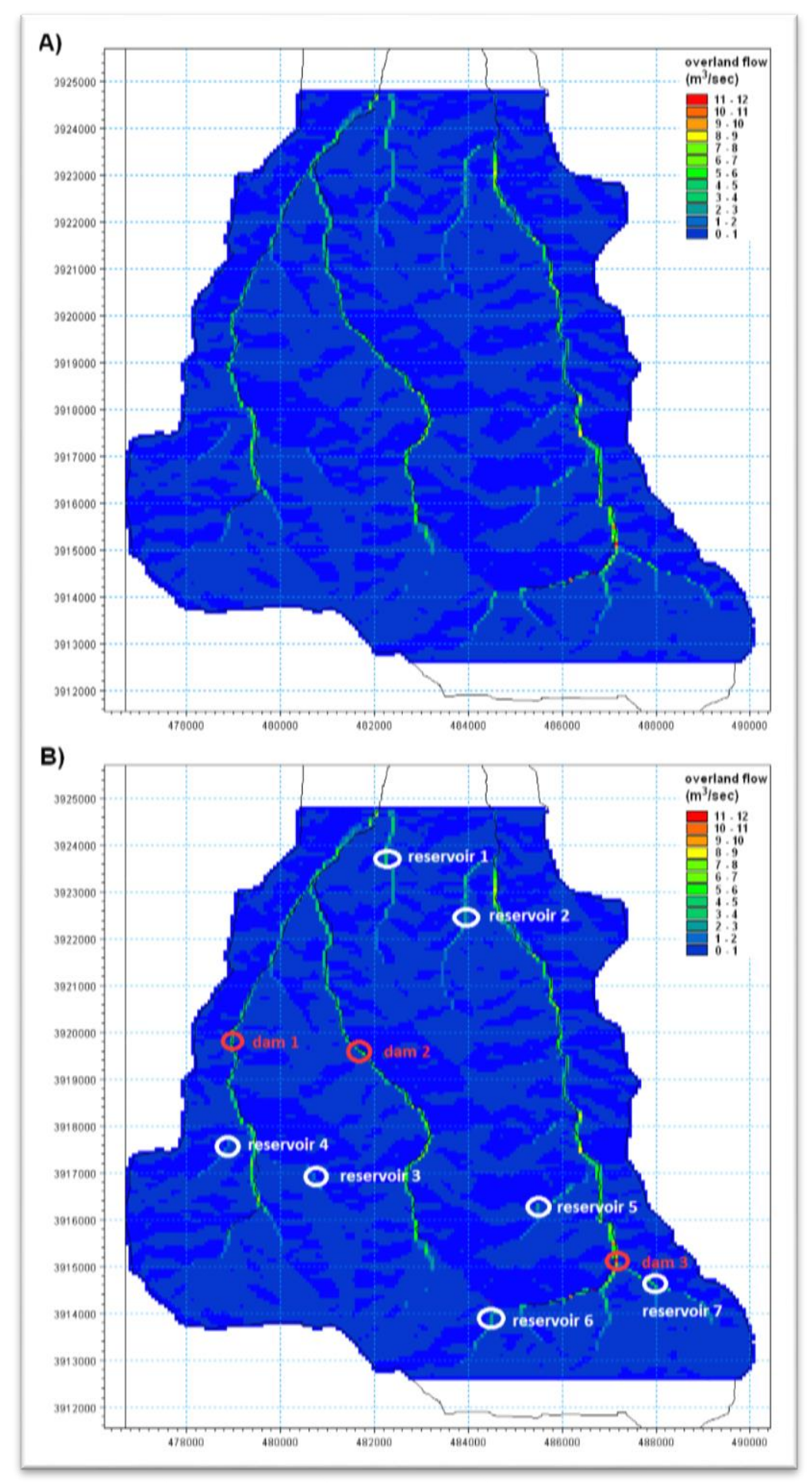

Figure 4. A) The 2D overland flow results, and B) proposed locations and hydraulic structures

The very good correlation between field flow measurements and the simulation results is shown in Figure 2 , for the calibration period 01/09/2000 - 31/08/2001 and at each of the two measurement locations (FM1, FM2). Moreover, in this figure various statistical indices are presented verifying the very good calibration process. For instance, the correlation coefficient $(R)$, is approximately equal to 0.86 for location FM1 (Roumatianos tributary) and 0.92 for location FM2 (Semproniotis tributary). In addition, the river flow measurements are in good agreement with the simulated results for both very low (drought periods) and very high (wet periods) flow rates. 
For the validation time period (01/09/2001 - 31/08/2003), the simulated results were compared with the existing flow measurements at locations FM1, FM2 (Figure 3) where a good agreement was found with the correlation coefficient (R) value to be equal to 0.74 for location FM1 (Roumatianos tributary) and 0.77 for location FM2 (Semproniotis tributary). Figure 3 shows that for the validation time period the river flow measurements are in good agreement with the simulation results for low flow rates as well as for sharp high flow peaks. Based on the statistical analysis of the model results the MIKE SHE simulation can be characterized as satisfactory for both extreme low flows and for flash flood events.

As it can be observed from Figure 3 the validation time period is related to two extreme hydrological years, where one of them is very dry (01/09/2001 - 31/08/2002) and the other one is very wet (01/09/2001 - 31/08/2003). Thus, the validation results were considered as an indicative time period for designing an appropriate agricultural water management plan for the study semi-mountainous area. Based on the above, the validated overland flow results were presented by a 2D space map. On this map (Figure 4A) the locations of significant surface water accumulation of the study region can be identified.

\subsection{Olive trees water management plan}

Determining the olive trees irrigation requirements, it is necessary to determine the crop evapotranspiration. The olive tree evapotranspiration $\left(E T_{\text {crop }}\right)$ is calculated by the following equation (Tsanis et al., 1997):

$$
\mathrm{ET}_{\text {crop }}=\mathrm{k}_{\mathrm{c}} \mathrm{ET}_{\mathrm{o}}
$$

where

$\mathrm{ET}_{\text {crop }}=$ olive tree evapotranspiration $\left[\mathrm{mm}_{\mathrm{year}}{ }^{-1}\right]$

$\mathrm{k}_{\mathrm{c}}=$ empirical olive tree coefficient per growing stage

$\mathrm{ET}_{\mathrm{o}}=$ reference evapotranspiration $\left[\mathrm{mm}_{\mathrm{m}} \mathrm{ear}^{-1}\right]$

According to Tsanis et al., (1997) the reference evapotranspiration $\left(E T_{o}\right)$ in the extended study area is estimated to be $2010 \mathrm{~mm}_{\text {year }}{ }^{-1}$.

The empirical olive tree coefficient $\left(k_{c}\right)$ is linearly interpolated between the initial, mid and late growth stages. For olive trees the average crop coefficient in the south part of Greece is $k_{c}=0.45$ (Tsanis et al., 1997). Based on the hydrological cycle concept, part of the rainfall water percolates below the root zone of the plants and part of the rain water becomes surface run-off. This deep percolated water and the surface run-off water cannot be used by the plants. The remaining part is stored in the root zone and can be used by the plants. This remaining part from an agricultural point of view is the effective rainfall ( $\left.P_{\text {eff }}\right)$, (Brouwer and Heibloem, 1986). Based on the above, and according to the empirical equations proposed by the USDA Soil Conservation Service Method that are widely applied for assessing the irrigation needs in Crete, the irrigation requirements of a specific olive tree area can be estimated. These equations are the following (Tsanis et al., 1996; Smith, 1992):

$$
\mathrm{IRR}_{\text {eq }}=\mathrm{A}\left(\mathrm{ET}_{\text {crop }}-\mathrm{P}_{\text {eff }}\right)
$$

where

$\mathrm{IRR}_{\text {eq }}=$ irrigation requirements $\left[\mathrm{m}^{3}\right.$ year $\left.^{-1}\right]$

$A=$ olive tree area $\left[10^{3} \mathrm{~m}^{2}\right]$

$\mathrm{ET}_{\text {crop }}=$ olive tree evapotranspiration $\left[10^{-3} \mathrm{~m}_{\text {year }}{ }^{-1}\right]$

$P_{\text {eff }}=$ effective rainfall $\left[10^{-3} \mathrm{~m}_{\text {year }}{ }^{-1}\right]$

$$
\begin{array}{ll}
P_{\text {eff }}=P_{\text {tot }} \frac{\left(125-0.2 P_{\text {tot }}\right)}{125} & \text { for } P_{\text {tot }}<250 \mathrm{~mm} \\
P_{\text {eff }}=125+0.1 P_{\text {tot }} & \text { for } P_{\text {tot }} \geq 250 \mathrm{~mm}
\end{array}
$$

where 
Peff: effective rainfall $[\mathrm{mm} / \mathrm{month}]$

$P_{\text {tot }}$ : total precipitation $[\mathrm{mm} / \mathrm{month}]$

A common water management practice in mountainous and semi-mountainous areas for irrigation purposes is the construction of small reservoirs in valleys or close to streams. Another practice is the construction of small scale dams, along the river line for collecting and storing winter runoff. In this way, many areas can be protected from an oncoming extreme hydrological event (flood - drought). In addition, from an ecological and environmental point of view, these hydraulic structures should be designed and operated to collect only part of the surface water in order to avoid drought conditions at the downstream sections of the river (Thornton et al., 1982). Based on the above, and taking into consideration the 2D modeling time-space flow accumulation results, different locations for the construction of small scale hydraulic structures can be proposed. Specifically, Figure 4B indicates seven locations for constructing reservoirs (white cycles) and three locations for small scale dams (red cycles). All these locations were selected considering several aspects such as: the large amount of surface water accumulation, the small distance from the olive tree cultivations and the relatively steeper slope of the energy grade line, avoiding the extra economic cost of pumping. Table 1 shows the accumulated water volume in $\mathrm{m}^{3} / \mathrm{year}$ for the hydrological years 2001-2002 (dry year) and 2002-2003 (wet year) at each proposed location.

In the study area, during summer the streams are dry and irrigation demands are higher, therefore water storage is necessary. In this work, to avoid the lack of irrigation water during the dry months, the requirements of the irrigation water are calculated using the accumulated water volumes of the extreme dry hydrological year 2001-2002 as the worst case scenario. For each of the proposed hydraulic structure, the available for irrigation water is considered to be $50 \%$ of the entire water volume that can be accumulated in any extreme dry year. Based on this assumption, and using Equations 1, 2, and 3 Table 1 shows for each proposed hydraulic structure the total olive tree area that can be irrigated for both extreme dry and wet hydrological years.

Regarding the water volume that can be accumulated at each hydraulic structure, Table 1 shows that the largest water volume can be collected at the location indicated as "dam 3", which could irrigate 350 to 2821 ha of olive tress depending on the hydrological conditions of the year. The second largest volume can be collected at the location indicated as "reservoir 7" which could irrigate 274 to 1233 ha of olive trees, depending on the hydrological year.

Table 1. Accumulated water volume $\left(\mathrm{m}^{3} /\right.$ year) and covered irrigated area (ha) for each hydraulic structure, for both wet and dry hydrological years.

\begin{tabular}{ccccc}
\hline $\begin{array}{c}\text { Proposed position } \\
\text { for hydraulic } \\
\text { structure }\end{array}$ & $\begin{array}{c}\text { Accumulated } \\
\text { Water }\left(\mathbf{m}^{\mathbf{3}} / \mathbf{\text { year}}\right), \\
\text { dry hydrological } \\
\text { year 2001-2002 }\end{array}$ & $\begin{array}{c}\text { Accumulated } \\
\text { Water }\left(\mathbf{m}^{\mathbf{3}} / \text { year), }\right. \\
\text { wet hydrological } \\
\text { year 2002-2003 }\end{array}$ & $\begin{array}{c}\text { Irrigated Olive } \\
\text { trees area (ha), } \\
\text { dry hydrological } \\
\text { year2001-2002 }\end{array}$ & $\begin{array}{c}\text { Irrigated Olive } \\
\text { trees area (ha), } \\
\text { wet hydrological } \\
\text { year 2002-2003 }\end{array}$ \\
\hline reservoir 1 & 891665.16 & 1895265.72 & 151 & 719 \\
reservoir 2 & 713117.02 & 1064199.47 & 121 & 404 \\
reservoir 3 & 377520.79 & 546475.96 & 64 & 207 \\
reservoir 4 & 246126.51 & 1065729.04 & 42 & 404 \\
reservoir 5 & 706739.59 & 1037110.64 & 120 & 394 \\
reservoir 6 & 1186263.10 & 1779441.73 & 201 & 675 \\
reservoir 7 & 1616378.90 & 3249658.37 & 274 & 1233 \\
dam 1 & 398172.97 & 1926788.01 & 67 & 731 \\
dam 2 & 980353.49 & 3325717.86 & 166 & 1262 \\
dam 3 & 2065214.70 & 7433021.75 & 350 & 2821 \\
\hline
\end{tabular}

\section{Conclusions}

The major problem faced in agriculture is the unavailability of irrigation water for the non-rainy cropping season. Especially, in impermeable semi-arid agricultural regions, where groundwater resources are very 
limited and it is expensive to pump, the proper management and control of surface water can significantly reduce the danger of drought and desertification. Thus, simulation models can be an effective tool to manage surface water and design efficient hydraulic structures for irrigation proposes. The integrated hydrological model MIKE SHE allows for the continuous monitoring of surface water accumulation at every grid point of the simulation area. The overland surface flow was estimated by a successful calibration and validation processes based on stream flow time series data ( 3 years) at two locations. Regarding the calibration and validation of surface flow, the results were in good agreement with the corresponding field measurements. Indicative values of the correlation coefficient R range from 0.74 to 0.92 . Next, a proper irrigation plan was designed based on the olive trees requirements for an extreme dry and an extreme wet hydrological year. In addition, based on the 2D overland flow several locations for the construction of small scale hydraulic structures (dams or/ and reservoirs) were proposed.

\section{References}

Abbott M.B., Bathurst J.C., Cunge J.A., O'Connel P.E. and Rasmussen J. (1986), An Introduction to the European Hydrological Systems-Systeme Hydrologique Europeen, 'SHE'. 2, Structure of a Physically Based Distributed Modelling System, Journal of Hydrology, 87, 61-77.

Abramowitz M. and Stegun I.A. (2012), Engineering statistics Handbook.3.3.24 NISTSEMATECH E-Handbook of Statistical Methods (accessed February 2014), National Institute of Science and Technology.

Brouwer C. and Heibloem M. (1986), Irrigation water management: Irrigation water needs. Rome: FAO.

Chartzoulakis K.S., Paranychianakis N.V. and Angelakis A.N. (2001), Water resources management in the island of Crete, Greece, with emphasis on the agricultural use, Water Policy, 3, 193- 205.

Corine Land Cover 2000 for Greece, European Environmental Agency.

Demetriou C. and Punthakey J.F. (1999), Evaluating Sustainable Groundwater Management Options Using the MIKE SHE Integrated Hydrogeological Modelling Package, Environmental Modeling and Software, 14, 129-140.

DHI, 2007. Mike SHE: an integrated hydrological modelling system. Documentation and users guide.

Frana A.S. (2012), Applicability of MIKE SHE to simulate hydrology in heavily tile drained agricultural land and effects of drainage characteristics on hydrology. Graduate Theses and Dissertations. lowa State University.

Fry L.M., Hunter T.S., Phanikumar M.S., Fortin V. and Gronewold A.D. (2013), Identifying streamgage networks for maximizing the effectiveness of regional water balance modeling, Water Resources Research, 49(5), 2689-2700.

Graham D.N. and Butts M.B. (2005), Flexible, integrated watershed modelling with MIKE SHE. In Watershed Models, Eds. V.P. Singh \& D.K. Frevert Pages 245-272, CRC Press.ISBN: 0849336090.

Im S., Kim H., Kim C. and Jang C. (2009), Assessing the impacts of land use changes on watershed hydrology using MIKE SHE, Environmental Geology, 57(1), 231-239.

Jayatilaka C.J., Storm B. and Mudgway L.B. (1998), Simulation of Water Flow on Irrigation Bay Scale with MIKE SHE, Journal of Hydrology, 208, 108-130.

Kourgialas N.N. and Karatzas G.P. (2011), Flood management and a GIS modeling method to assess flood hazardous areas - A case study, Hydrological Sciences Journal, 56(2), 212-225.

Kourgialas N.N. and Karatzas G.P. (2014), Groundwater contamination risk assessment in Crete, Greece using numerical tools within a GIS framework, Hydrological Sciences Journal, DOI:10.1080/02626667.2014.885653.

Kourgialas N.N., Dokou Z. and Karatzas G.P. (2015), Statistical Analysis and ANN Modeling for Predicting Hydrological Extremes under Climate Change Scenarios - The example of a small Mediterranean Agro-watershed, Journal of Environmental Management, 154, 86-101.

Moriasi D.N., Arnold J.G., Van Liew M.W., Bingner R.L., Harmel R.D. and Veith T.L. (2007), Model evaluation guidelines for systematic quantification of accuracy in watershed simulations, Transactions of the ASABE, 50(3), 885-900.

Pestana R., Matias M.P., Canelas R., Roque D., Araújo A., Van Zeller E., Trigo-Teixeira A., Ferreira R., Oliveira R.P., Heleno S., Falcão A.P. and Gonçalves A. (2014), Calibration of 2D hydraulic inundation models with SAR imagery in the floodplain region of the Lower Tagus River. European Geosciences Union General Assembly 2014. 
Rahim Bahaa-eldin E.A., Yusoff I., Jafri A.M., Othman Z. and Abdul Ghani A. (2012), Application of MIKE SHE modelling system to set up a detailed water balance computation, Water and Environment Journal, 26(4), 490-503.

Sahoo G.B., Ray C. and De Carlo E.H. (2006), Calibration and validation of a physically distributed hydrological model, MIKE SHE, to predict streamflow at high frequency in a flashy mountainous Hawaii stream, Journal of Hydrology, 327(1-2),94-109.

Singh R., Subramanian K. and Refsgaard J.C. (1999), Hydrological Modelling of a Small Watershed Using MIKESHE for Irrigation Planning, Agricultural Water Management, 41, 149-166.

Smith M. (1992), CROPWAT - A Computer Program for Irrigation Planning and Management; Irrigation and Drainage Paper 46; Food and Agriculture Organisation: Rome, Italy, 1992.

Thornton K.W., Kennedy R.H., Magoun A.D. and Saul G.E. (1982), Reservoir water quality sampling design, Water Resources Bull., 18, 471-480.

Tsanis I.K., Koutroulis A.G., Daliakopoulos I.N. and Jacob D. (2011), Severe climate-induced water shortage and extremes in Crete, Climatic Change,106(4), 667-677.

Tsanis I.K., Londra P.A. and Angelakis A.N. (1997), Assessment of Water Needs for Irrigation in Greece, Acta Hort. (ISHS), 449:41-48, http://www.actahort.org/books/449/449_4.htm

Vázquez R.F. and Feyen J. (2007), Assessment of the Effects of DEM Gridding on the Predictions of Basin Runoff Using MIKE SHE and a Modelling Resolution of 600 m, Journal of Hydrology, 334, 73-87. 